\title{
A Review of Negative Language Transfer Regarding the Errors in English Writing in Chinese Colleges
}

\author{
Xiaoyu Yang \\ School of Foreign Languages, Tianhe College of Guangdong Polytechnic Normal University, China
}

\begin{abstract}
It is generally recognized that English as a Second Language is popular with language learners in China. As a major section of language learning, English writing often takes on an important role in English language learning for Chinese students. Many learners would be easily impeded by their mother tongue, Chinese and would therefore make some mistakes from time to time when it comes to writing in English. This is a pervasive phenomenon in the field of Second Language Acquisition research. Based on the relevant theories of Language Transfer, Negative Language Transfer, and Error Analysis, in terms of global research, especially in China, the current review focuses on the errors caused by the negative language transfer, and chiefly tries to probe into the suggestions to avoid such negative transfer influences in English writing among Chinese learners.
\end{abstract}

Index Terms - language transfer, negative language transfer, errors analysis, English writing

\section{INTRODUCTION}

As is known to all researchers of Second Language Acquisition (SLA), broadly speaking, language transfer is a hot topic in this domain (Odlin, 1989). All over the world, as well as in China, extensive studies have been carried out on Cross-linguistic transfer by prior researchers in history. With the aim of exploring the extent of writing errors of negative language transfer studies to date, relevant research in the literature concerning transfer, negative transfer (from 1945 until now), have been reviewed in the current paper in a chronological order. In the article, the writer makes an attempt to provide the answers to the research question: what kinds of writing errors of negative language transfer have occurred in today's Chinese English learners' writing and what has been done to solve these problems? It could be anticipated that common errors in English usage have been found and, accordingly, many solutions have been given, but the field is still under research. Hence, this issue is worth more attention in depth.

The review includes five sections. The first section is the present introduction section in question. The second section gives a historical account of the role of transfer in general, or rather; identify the key themes in the field, which consists of the Notion of Transfer, the general Research Purpose, the Dimension of Transfer Research, the Positive and Negative Transfer and key terms in relation to Negative Transfer. The third section introduces the relevant theories such as Error Analysis and Interlanguage; as the main body of the article, the fourth section begins with the current situation of English writing in China and provides a growing body of literature review on negative transfer in English writing among Chinese learners. Finally, a conclusion is given to identify the gaps in the current knowledge, and the possible future investigation is shown to address the gaps in English education of China.

\section{LANGUAGE TRANSFER}

\section{Notions of Transfer and Its Development in History}

In the field of SLA, the notion of Cross-linguistic transfer has been discussed by various researchers for a long time. Since the term 'transfer' varies among researchers, to clarify the definition of the term is of paramount importance. Historically, Lado (1957) maintains that the phenomenon of transfer was that "Individuals tend to transfer the forms and meanings, and the distribution of forms and meanings of their native language and culture to the foreign language and culture" (p.2). For Selinker (1966), language transfer means "a process occurring from the native language to the foreign language if frequency analysis shows that a statistically significant trend in the speaker's native language" ( $p$. 103). Later, in 1989, Odlin popularizes the term by identifying that "transfer is the influence resulting from similarities and differences between the target language and any other language that has been previously (and perhaps imperfectly) acquired" (p.27). Therefore, acquired language not only refers to first language (L1); perhaps a second language (L2) or other languages are involved as well. However, for the most part, acquired language often refers to L1 and target language chiefly refers to L2 in most language transfer studies. In addition, Odlin (1989) emphasizes "the performances of speakers of at least two different native languages" (p. 32), which focuses on the comparisons between interlanguage-interlanguage (IL-IL) (Javis, 2000). Afterwards, in the light of what Selinker's idea (1992), transfer is "operationally defined as a process which occurs whenever a statistically significant... [pattern in the L1] reappears in 
IL behaviour" (p.201). Selinker highlights the "L1-IL comparisons" (Javis, 2000, p. 251). Furthermore, transfer is defined by Mayer and Wittrock (1996) as "the effect of knowledge that was learned in a previous situation (task A) on learning or performance in a new situation (task B)" (p. 48).

Nonetheless, even though only some definitions are introduced above, multiple definitions of transfer reveal a general situation, which is that, as discussed by Dechert and Raupach, more than ten different definitions of transfer occurred in literature (Javis, 2000). But first language (L1) influence remains a "you-know-it-when-you-see-it phenomenon" (Javis, 2000, p.246). Though numerous studies had discussed its effect, there was no accepted agreement of the definition of L1 influence (Javis, 2000). Based on the differences of what Odlin (1989) and Selinker (1992) said, from a methodological heuristic perspective, Javis (2000) also proposes that "L1 influence refers to any instance of learner data where a statistically significant correlation (or probability-based relation) is shown to exist between some feature of learner's IL performance and their L1 background" (p. 252), which developed the concept of transfer as well. In regard to L1 influence, Javis also summarised three aspects of effects including "intra-L1-group homogeneity in learners' IL performance", which refers to "learners who speak the same L1 behave in a uniform manner when using the L2" (p.254), "inter-L1-group heterogeneity in learners' IL performance", which "is found when comparable learners of a common L2 who speak different L1s diverge in their IL performance" (p.254), and "intra-L1-group congruity between learners' L1 and IL performance" that means "where learners' use of some L2 feature can be shown to parallel their use of a corresponding L1 feature"(p.255). These effects should be combined with any of others to substantiate the existing of transfer (Javis, 2000).

The above-mentioned conceptions later gave rise to new ones. Apart from the emphasis of first language influence on second language study, there is yet another definition focusing on the interactions between two languages. For example, Chen (2006) claims that, "the term transfer implies more than simply the effects of the L1 on the L2; the L2 also influences the L1" (Brown 2000, Su 2001, Cook 2003, cited in Chen, 2006, p.148), which correspondingly, expanded the definitions of transfer as well. It could be observed that the notion of transfer is still updated by researchers in the field of SLA to date. As the current topic would pay attention to the negative influence of L1 transfer, the effects of L2 on L1 would not be discussed in detail.

\section{General Purpose of Transfer Research}

From 1950 to 1960, theories about language transfer are the main topic in Second Language Acquisition (Yu, 2010). According to Jarvis and Pavlenko (2008), "the ultimate goal of transfer research is the explanation of how the languages a person knows interact in the mind" (p.111, cited in Javis\& Crossley, 2012, p. 10). In addition, Javis and Crossley (2012) indicate four types of transfer research, concerning: "the pursuit of empirical discoveries", "theoretical advances", "the development of methodological tools", "the development of an argumentation framework" (p.10), which could be interacted with each other in numerous research. Much research that concentrated on the exploration of evidence would be presented in the following.

\section{Dimensions of Transfer Research in the Globalized World}

For one thing, the phenomenon of transfer could be found from many aspects in language acquisition, such as syntax transfer, lexical studies, phonetics, conceptual ideas, spelling skill and so forth, for another, from learners with different proficiency. It could be attested to by many studies in the global arena. For instance, Helmspark (2003) carried out an investigation among Vietnamese ESL learners and found that, compared to Hindi-Urdu, a non-serializing language, Vietnamese-speaking participants were inclined to produce serial-type constructions that bear a resemblance to Vietnamese, which corroborated evidence of the syntactic transfer. Additionally, Chan (2004) found evidence in Hong Kong that Chinese ESL learners preferred adopting sentence structure in the light of their L1, Cantonese, and Chinese way of thinking. Chan also figured out that the transfer would be more complicated when the target language is more difficult in structure. Typically, the lower is learners' level of proficiency, the more obvious their syntactic transfer is likely to be. Moreover, Ping and Rickard (2011) investigated whether morphophonemic Malay-knowledge influences English-processing by manipulated junctural phonetics or not. Their results provided strong empirical evidence that adults experience Malay L1 to English L2 morphophonemic transfer. Similarly, Bagherian (2012) scrutinized the concept of Persian and English and carried out an investigation on 100 Iranian learners. The data of Bagherian's study corroborated the evidence that the learners went through a conceptual transfer from their L1 Persian to L2 English. More recently, Yeon, Bae and Joshi (2017) examined English spelling from 287 Korean children from the fourth, fifth, and sixth grades, and found that Korean metalinguistic awareness significantly controlled the English vocabulary. In particular, the Korean morphological awareness and phonological awareness, which were caused by metalinguistic awareness could explain the English spelling. The empirical study confirmed that metalinguistic awareness transfer had an impact on the development of second language spelling. It could be seen that the study of transfer provided significant evidence of transfer and the latter clearly demonstrated that the language transfer is everywhere in second language development, which reaches a large scale.

\section{Classification of Transfer and Negative Transfer}

Also, transfer has been classified into many aspects. In Dai and Wang (2002)'s research, they suggest that, based on those studies done by Wang (1990), Xu (1992), Ellis (1994), Odlin (2001), and others the similarities and differences of cross-linguistic would produce the following outcomes (p.5). The first is positive transfer, which could only be confirmed by learners with different background (Dai, \& Wang, 2002). As to the specific concept of positive transfer, 
Odlin (1989) contended that learner's L1could improve the learning of L2, which could be generally regarded as Positive transfer. For instance, similar vocabularies would improve the reading ability in foreign language learning (Dai, \& Wang, 2002). The second one is negative transfer, which is also classified into three categories, first, including "underproduction" (Odlin, 1989, p. 36; Dai, \& Wang, 2002. p.5), which occurs when learners are not familiar with the target language, and therefore, they would choose structures that are less frequently used by native speakers instead; second, "overproduction" like using too much apology in American English (Odlin, 1989, p. 36; Dai, \& Wang, 2002.p.5); and third, the "production errors", which consists of substitution, calque, the change of structure and so on (Odlin, 1989, p. 36; Dai, \& Wang, 2002.p.5), and finally, "mis-interpretation", which causes the misunderstanding in that the structure of mother tongue has an impact on the understating of the target language (Odlin, 1989, p. 36; Dai, \& Wang, 2002.pp 5-6). And the third one is the "different lengths of acquisition" (Odlin, 1989, p. 36; Dai, \& Wang, 2002.p.6).

As already mentioned, not only positive transfer exits in the development of second language learning, but also negative transfer. The term negative transfer has been known as interference occurred in numerous research. There have been a number of studies in second language development touching upon the errors produced by the negative transfer (Wang, 2009). This can be illustrated briefly by Figueredo's paper, in terms of Spelling Skill, from the review done by Figueredo (2006), researchers proved that both positive and negative transfer influenced the spelling of ESL learners. Typically, negative transfer is one of the most important aspects relating to cross-linguistic evidence. According to the classification done by other researchers, it had already shown its complexity as well. In the light of what Odlin (1989) says, it could be predicted that when two languages show more differences, more negative transfers would occur. Brown rendered that negative transfer would hinder the performance of target tasks (Yang, Ma \& Cao, 2013). In the following sections, information on negative language transfer would be gathered and synthesised in detail.

\section{ERROR ANALYSIS AND INTERLANGUAGE}

\section{Errors and Mistakes or Lapses}

With respect to errors, of course, errors here refer to language error in the field of SLA. First and foremost, the distinction between errors and mistakes or lapses should be made (Corder, 1975). According to Corder (1975), errors, "typically produced by people who do not yet fully command some institutionalised language system" (p.204). From Corder's point of view, making errors is unavoidable and it is an essential part of learning (Yu, 2010). In contrast, mistakes or lapses refer to "failures to utilise a known system correctly" (Corder, 1971a, cited in Corder, 1975, p. 204). In this sense, what the current review focuses in question are errors instead of mistakes or lapses.

Generally speaking, errors in linguistic area include morphological, syntactic, lexical, semantic, pragmatic errors and so forth. Lado (1957), contended that the performance of erroneous language could be viewed as the mother tongue's transfer to the target language. In this case, errors were caused by the interference, or rather, negative transfer, and teaching could solve those problems (Lee, 1970). Such a concept facilitated the development of "Contrastive linguistics" (Corder, 1975).

Specifically speaking, errors could also be classified into inter-lingual errors and intra-lingual errors (Richards, 1974). Because of the interference of native language, Inter-lingual errors occurred (Richard, 1974). To be exact, it is interlingual errors which would be discussed in the following literature.

\section{Errors Analysis and Interlanguage}

Lado (1957) paves the way for the Contrastive Analysis Hypothesis (CAH) after it was developed by Fries (1945). According to Behaviourists, the obstacle to second language acquisition was the interference of the mother tongue. Thus, it was necessary to do the contrastive analysis to figure out the differences and then predicted the faults and corrected it during the process of learners' second language development. Consequently, later, Error Analysis, which referred to the systematic and analytical study about the errors made by second language learners, was born in the late 1960s and the early 1970s and first advocated by Pit Corder. For instance, Svartvik (1973) suggests that error analysis should be used for "the study of erroneous utterances produced by groups of learners at some stage of their learning career" (Corder, 1975, p. 205). In summary, Error Analysis served the functions of pedagogy and expanded the comprehension of the second language learning (Corder, 1975).

During the same period, the term of interlanguage, which stands for 'language between the native language and the target language', was introduced by Selinker (1972). The concept of interlanguage can be traced back to 1967, which was the year that Coder put forward the concept of "transitional competence" to describe a state that language learners have not yet reach the level of mastering that second language (Yu, 2010). Interlanguage focuses on the "intermediate status of the learner's language system", which admitted the "literature of error analysis" (Zydatiss, 1974 a; Strvens, 1969, cited in Corder, 1975, p.204). So, it directly relates to the current issue in question.

\section{Writing of Negative Transfer AMONG CHINESE LEARnERS}

\section{Chinglish Writing and English Writing Research in China}

It is generally known that English and Chinese are two different systematic languages. During the long period of English learning in China, there has been a phenomenon called Chinglish. Li (1993) defined that "Chinglish refers to 
the Sinicized English usually found in pronunciation, lexicology and syntax, due to the linguistic transfer or 'the arbitrary translation' by the Chinese English learners, thus being regarded as an unaccepted form of English" (p. 18), which could be regarded as a generalisation of errors in English writing as well. People would come across it quite often in English writing from Chinese learners.

Chinese learners are encouraged to study English irrespective of their age and educational level. Regarding to English College Education, more and more attention has been paid to English proficiency by the Chinese government, Ministry of Education and even the whole country. There are four main skills to be checked in English assessment of college students. Writing is still one of the most important parts in the second language learning throughout China. Nonetheless, as described in Yu's paper in 2010, even though teachers and students paid much attention to it, the writing skill was hard to be improved (p.20). Hence, it appealed to researchers of English teaching in China, particularly the writing teaching experts and scholars, who have explored and discussed its improvement in depth (Yu, 2010, p.20).

Regarding those studies about English writing, since the 1980s, the research on English writing had been developed in China (Yu, 2010). Great changes happened on the contents, quantity, methodology etc. of writing studies (Yu, 2010). From a diachronic perspective, in Zhang, Yan and Liu's presentation in 2015, it was concluded that during the ten years from 2004 to 2014, though much research were expanded to the K-12 level in 2014, the majority of studies concerning EFL writing remains to pay attention to the college-level instruction or assessment as well. Many studies concerning teaching approaches in EFL writing have been conducted by researchers (Zhang, Yan \& Liu, 2015).

\section{Writing Errors and Pedagogical Suggestions}

Kaplan (1972) indicates that Cross-cultural differences in rhetoric produced those problems in academic writing by English as a Second Language learners. Similarly, the situation of China is in agreement with those general phenomena of transfer research in the world. Firstly, myriad studies have been conducted by many researchers. Secondly, in most cases, English, is regarded as the target language in much of the research (Chan, 2004). Among those English as a Second Language learners, learners of Chinese as L1 accounted for the majority (Cortazzi \& Jin, 1996; Dzau, 1990, cited in Chan, 2004). Evidence from Juffs (1996), Schachter (1974), and Schachter and Rutherford (1983), all demonstrated that, from L1 Chinese to L2 English, there are "negative transfer "existing at "phonological", "lexical", "syntactic", "semantic", and "discourse levels" (Chan, 2004, p. 57).

Much research provided evidence that demonstrates, the study of Chinese negative transfer proceeded from the 1980s in China (Li \& Liu, 2010), particularly in writing. There are many typical errors from Chinese learners in producing English which could be found out in that researchers had contributed a lot on negative transfer and error analysis over the decades. Key findings offer the evidence that confirmed the writer's view and provides the counter argument. For example, Mohan and Lo in 1985 not only scrutinize that the academic writing by L2 learners were attributed to native language's negative transfer, but also discussed developmental factors for it. Their findings called for student's awareness of native literacy as well as educational experience as factors for writing.

During this decade, much research still struggled to probe into the development of avoiding negative transfer in English writing. These studies shared many similarities as follows:

In review of the existence of negative transfer in Chinese students, such as the Chinese interference of grammar, lexicons, Deng (2001) claimed that such a phenomenon was as a result of the inefficient input of target language. Accordingly, Deng emphasized the importance of recitation which could bring greater impact on English writing teaching. Qiu and Ling (2003) pointed out the negative transfer of Chinglish writing in college non-English major students' writing, and put forward some strategies to cope with it. From the perspective of teachers, Qiu and Ling emphasized that the language input should be strengthened by teachers and, similar to Deng (2001), they shared the same ideas that students should be exposed to more recitation as well. He (2005) made comparison on the thinking modes and discourse structure between China and West and discussed the reasons why English-majors made errors in their English writing. Li (2007) focused on the existence of Chinglish through analysing evidence of negative language transfer in the aspects of morphemic, lexical, syntactical and discourse level and additionally, provided some educational strategies, such as "Reinforce the Input of Language Knowledge", "Reinforce the Input of Culture Knowledge", "teach writing as a process" (pp.93-94). Dong and Han (2009) concentrated on negative transfer errors and analysed them from the lexical and syntactic aspects. Above all, it could be observed that previous papers written in different years in the past decades all paid attention to the evidence of negative transfer phenomena and some of them have tried to work out some ways to correct errors.

Finally, concerning recent years - from 2010 to now, there are still many studies regarding the negative language transfer in English writing as well. With more rigors in the studies, more and more researchers participated in the searching of negative language transfer and it has been expanded not only its evidence but also practical teaching suggestions on it, particularly in many colleges throughout China. Representative studies are presented in the following:

Yu (2010) prepared questionnaires for students and teachers to know the state of negative transfer. The students were English Education students from a Normal University in China. The result of Yu's survey showed that students went through the interference from negative transfer of their mother tongue, which was mostly in relation to L1 thinking. Most errors resulted from L1 thinking were as follows: inappropriate usage of article, words, sentence structure, Chinese discourse level, which made it harder for students to convey ideas in formal English.

Based on the comparison between Chinese and English in words, words phrases and sentences, Li (2011) also 
confirmed that errors in writing were mainly caused by Chinese logical thinking. Consequently, Researchers argued that teachers should cultivate the awareness of cross-cultural communication, introduce relevant theories about English Language as well as develops the habits of thinking in English.

Wang and Feng (2012) investigated 60 sophomore non-English major students' College English Band 4(CET-4, a national test in China) composition at the syntactic level, which affirmed that Chinglish sentences are quite frequent. Wang and Feng suggested teachers should provide more input to the students like reading or writing more as well, which has already been emphasized in the past research.

In Yang, Cao and Ma (2013)'s research, they analysed the lexical negative transfer among Chinese in English as a foreign language writing and found three main errors type, including "errors in word choice, errors in derivation, and those in collocation" (p.669). In addition, Yang, Cao, and Ma, proposed some pedagogic suggestions to solve these problems, such as "Encouraging learners to think in Native ways", "Providing necessary language input for the students", "Making Contrastive Analysis of Chinese and English", "Building up a good knowledge of English vocabulary and grammar" (p.671).

Chen (2014) conducted a case study in Changchun Institute of Technology in China and selected 80 sophomores to write a composition. By concentrating on Chinese negative transfer in English writing, Errors analysis mainly paid attention to vocabulary. It was found that $58 \%$ of vocabulary errors were because of Chinese hindrances and what is more, meaning errors accounted for the most. In addition, questionnaires were done to study the reasons of errors production, which revealed that students were used to adopt inappropriate learning techniques. Chen also proposed some ideas to avoid the negative language transfer so as to provide pedagogical implications, such as "raising awareness of language transfer", "making Contrastive Analysis of English and Chinese", "Increasing Comprehensible Input and Culture Input", "Correcting Inter-lingual errors"(pp. 43-45).

Wang (2015) asked sixty-three second year language learners from Jiujiang University to write English compositions and mainly scrutinized the usage of attributive clauses, including five kinds of errors due to the negative influence, which was caused by the awareness or unawareness of influential Chinese mother tongue. Errors consist of "underused attributive clauses including avoidance strategy", "redundant pronoun or antecedent", "omission preposition", "underused", "misplaced or redundant relative words" (p.4). But how to improve the teaching method guidance for avoiding the influence of negative transfer was emphasized by the researcher.

Li (2016), chose 50 non-English major students in one university of Jiangxi, China. The data disclosed that firstly, students would be affected by the negative transfer more or less; secondly, non-English major learners depended on L1 strategy; thirdly, students were accustomed to employ the L1 strategy and the mode of Chinese logical thinking. As to teachers, researcher also pointed out that teachers should use teaching strategy to guide students to avoid such negative transfer. Simultaneously, teachers could create a real language learning atmosphere to facilitate the students to think in English and read more. Particularly, teachers should improve the vocabulary teaching in that non- English major were easily making errors in vocabularies and syntax. Finally, for one thing, error corrections and feedback should be given by teachers timely, for another, practices should be provided for self-correction and peer feedback so that avoiding the negative transfer in English writing.

To sum up, the above representative studies have described the common errors in English writing among Chinese learners from different language levels or aspects. It is common that language learners are used to thinking in a "Chinese way", or rather, thinking is modulated by L1 linguistic experience. Moreover, some researchers have contributed to provide pedagogical suggestions for teachers to avoid the bad influences of negative transfer in language writing in such a long period. However, the ability of these above studies to address negative transfer in China is limited. With so many studies conducted so far, the common problems are still discussed by researchers. It seems that writing errors from negative transfer is still a big problem that cannot be discounted in English writing and something new should be implemented to the current situation, which is of course, a long way to go in the future.

\section{DisCUSSION AND CONCLUSION}

From a neutral perspective, on the one hand, from the situation globally, compared to China, the current article has summarised the theories about language transfer, negative transfer and errors and, on the other hand, the evidence about the negative transfer from L1 to L2, more specifically, from Chinese to English, in a chronological order. Not only the errors about negative transfer could be found in the past research, but also many strategies are explored and put forward by many researchers in terms of how teachers could help language learners to avoid the influence of negative language transfer. What they have done has already brought a state of art in the field of negative transfer research.

Nevertheless, it is found that little research in the literature paid attention to the views of language learners on how to cope with negative transfer when they are writing their English articles. It should be stressed that learners are the most crucial protagonists who could determine if facilitating or retarding the development of their own writing ability. Therefore, how the students prefer to tackle their writing errors problems of negative language transfer and what the visions in their mind are, should be explored more detail in the future. Furthermore, learners with different proficiency levels are also another important factor that should be taken into consideration. The learners' proficiency level should be defined as a variable in new investigations. Research on these questions remains at a beginning stage throughout China. In short, adequate attention should be given in an attempt to provide more evidence in the domain of negative language 
transfer. By standing on the shoulders of the giants, investigations on how high-level students think and react to negative transfer errors can provide interesting ideas in the field and definitely enhance the English teaching in China.

\section{REFERENCES}

[1] Alice Y. W. Chan. (2004). Syntactic transfer: Evidence from the interlanguage of Hong Kong Chinese ESL learners. The Modern Language Journal, 88(1), 56-74. doi:10.1111/j.0026-7902.2004. 00218.x.

[2] Bagherian, A. (2012). EFL learners' 11 conceptual transfer and its relation to their language proficiency and age. International Journal of Applied Linguistics \& English Literature, 1(4), 152-160.

[3] Chen, F.J.-G. (2006). Interplay between forward and backward transfer in L2 and L1 writing: The case of Chinese ESL Learners in the US. Concentric: Studies in Linguistics, 32 (1), 147-196.

[4] Chen, F. (2014). On the negative transfer of vocabulary in non-English majors' writing. (Master thesis, China: Changchun University of Science and Technology).

[5] Corder, S. P. (1975). Error analysis, interlanguage and second language acquisition. Language Teaching, 8(4), 201-218.

[6] Dai, W., \& Wang, D. (2002). Language transfer studies: issues and reflections. Journal of Foreign Languages (6), 1-9.

[7] Deng, L. (2001). Attaching Importance to the Input of Recitation and Getting Rid of the Negative Transfer of Chinese in English Writing. Foreign Language Education, 22(4), 42-44.

[8] Dong, J, \& Han, G. (2009). Negative transfer in Chinese college students' English writing. Sino-US English Teaching (8), 9-16.

[9] Dulay, H. and Burt, M (1974). A new perspective on the creative construction processes in child second language acquisition. Language Learning 24, 253-268.

[10] Figueredo, L. (2006). Using the known to chart the unknown: A review of first-language influence on the development of English-as-a-second-language spelling skill. Reading and Writing, 19 (8), 873-905. doi:10.1007/s11145-006-9014-1.

[11] Fries, Charles C. (1945). Teaching and Learning a Foreign Language. Ann ARBOR: University of Michigan Press.

[12] Helmspark, R. (2003). Transfer in sla and creoles: the implications of causative serial verbs in the interlanguage of Vietnamese esl learners. Studies in Second Language Acquisition, 25, pages. 211-244.

[13] He, Q. (2005). The influences of negative transfer of native language for English-major students' writing. Journal of Hunan University of Science and Engine (3), 205-206.

[14] Jarvis, S. \& Pavlenko, A. (2008). Cross linguistic influence in language and cognition. New York and London: Routledge.

[15] Jarvis, S. (2000). Methodological rigor in the study of transfer: Identifying L1 influence in the interlanguage lexicon. Language Learning, 50, 245-309.

[16] Jarvis, S., \& Crossley, S. A. (Eds.). (2012). Approaching Language Transfer through Text Classification: Explorations in the Detection-based Approach (Vol. 64). Bristol, UK: Multilingual Matters.

[17] Kaplan, Robert B. (1972). The anatomy of rhetoric: prolegomena to a functional theory of rhetoric. Philadelphia: Center for Curriculum Development (Concord, Massachusetts: Heinle and Heinle).

[18] Lado, R. (1957). Linguistics across Cultures. Ann Arbor: University of Michigan Press.

[19] Lee, W. R. (1970). The Dolphin English Course- Teachers' companion. London: OUP.

[20] Li, W. (1993). China English and Chinglish. Foreign Language Teaching \& Research, 4, 18-24.

[21] Li, J. (2007). Negative language transfer in college English writing by Chinese students: problems and strategies. Celea Journal, 3(2), 88-103.

[22] Li, X. (2011). On negative transfer of L1 thinking in English writing. J. Shanxi Agric. Univ. (Social Science Edition), 10(8), 853-856.

[23] Li, Y. \& Liu, A. (2010). Chinese negative transfer on Chinese-English translation under inter-language theory and error analysis. Journal of Harbin University, 31(6),118-122.

[24] Li, L. (2016). An investigation on negative transfer for non-English major students' writing. Jiangxi Normal University, Jiangxi, China.

[25] Mayer, R. E., \& Wittrock, M. C. (1996). Problem-solving transfer. In D. C. Berliner \&R. C. Calfee (Eds.), Handbook of educational psychology (pp. 47-62). New York: Simon \& Schuster Macmillan.

[26] Mohan, B., \& Lo, W. (1985). Academic Writing and Chinese Students: Transfer and Developmental Factors. TESOL Quarterly, 19(3), 515-534. doi:10.2307/3586276.

[27] Odlin, T. (1989). Language Transfer: Cross-linguistic Influence in Language Learning. Cambridge: Cambridge University Press.

[28] PING, S. W., \& RICKARD LIOW, S. J. (2011). Morphophonemic transfer in English second language learners. Bilingualism: Language and Cognition, 14(3), 423-432. doi:10.1017/S1366728910000283.

[29] Qiu, J., \& Ling, B. (2003). Negative transfer of Chinese in English writing and its solutions. Journal of Zhejiang Education Institute (4), 96-101.

[30] Richards, J. (1974). Error Analysis: Perspectives on Second Language Acquisition. London: Longman.

[31] Selinker, L. (1966). A Psycholinguistic Study of Language Transfer. Ph.D. Dissertation. Georgetown University.

[32] Selinker, L. (1972). Interlanguage. International Review of Applied Linguistics, 10(1-4), 209-231.

[33] Selinker, L. (1992). Rediscovering interlanguage. London: Longman.

[34] Wang, Y. (2009). Research on three error types of Chinese esl learners' acquisition of passive voice. Asian Social Science, 5(12), 134-140.

[35] Wang, Y. \& Feng, Y. (2012). Negative Transfer of Mother Tongue in Non-English Majors' English Writing. Journal of Language and Literature Studies (9), 163-164.

[36] Wang, Y. (2015). Negative transfer of mother language in English compositions by Jiujiang university students. Paper presented at the, 14doi: http://dx.doi.org/10.1051/shsconf/20151401008.

[37] Yang, L., Ma, A., \& Cao, Y. (2013). Lexical Negative Transfer Analysis and Pedagogic Suggestions of Native Language in Chinese EFL Writing. In 2013 Conference on Education Technology and Management Science (ICETMS 2013). Atlantis Press. 
[38] Yeon, S., Bae, H. S., \& Joshi, M. (2017). Cross-language transfer of metalinguistic skills: Evidence from spelling English words by Korean students in grades 4, 5 and 6: Cross-language transfer of metalinguistic skills. Dyslexia, doi:10.1002/dys.1547.

[39] $\mathrm{Yu}, \mathrm{C}$. (2010). Negative transfer of mother tongue in English majors' English language writing: current situation and countermeasures. (Master thesis, China: East China Normal University).

[40] Zhang, C., Yan, X., \& Liu, X. (2015). The development of EFL writing instruction and research in china: An update from the international conference on English language teaching. Journal of Second Language Writing, 30, 14-18. doi: 10.1016/j.jslw.2015.06.009.

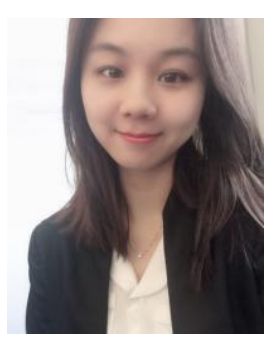

XiaoYu Yang is currently working in the School of Foreign Languages, Tianhe College of Guangdong Polytechnic Normal University, Guangzhou, China. She received her Master degree from the University of Reading, the United Kingdom.

Her research interests include second language acquisition, applied linguistics and psycholinguistics. 